\title{
Characterising biofouling communities on mussel farms along an environmental gradient: a step towards improved risk management
}

\author{
A. M. Watts ${ }^{1,2,3, *}$, S. J. Goldstien ${ }^{1}$, G. A. Hopkins ${ }^{2}$ \\ ${ }^{1}$ School of Biological Sciences, University of Canterbury, Christchurch 8041, New Zealand \\ ${ }^{2}$ Coastal and Freshwater Group, Cawthron Institute, Nelson 7010, New Zealand \\ ${ }^{3}$ Present address: National Institute of Water and Atmosphere (NIWA), 217 Akersten Street, Port Nelson, Nelson 7010, \\ New Zealand
}

\begin{abstract}
Biofouling pests can have significant economic impacts on aquaculture operations, including increased processing and production costs. An important first step towards improved biofouling management is understanding the density and distribution of the biofouling species within a growing region. In this study, biofouling communities were sampled from 73 commercial mussel farms within New Zealand's main mussel growing region, Pelorus Sound. At each farm, photoquadrats $\left(0.08 \mathrm{~m}^{2}, \mathrm{n}=6\right)$ of biofouling organisms were obtained at 2 depth ranges ( 3 per range) from suspended long-line droppers, both at the surface (0 to $3 \mathrm{~m}$ of the dropper) and bottom (9 to $24 \mathrm{~m}$, depending on dropper length and water depth). Biomass samples and visual estimates of biofouling biomass were also obtained. Strong spatial variation in the structure of biofouling communities was evident, with increasing dissimilarity between communities along Pelorus Sound. Problematic taxa (e.g. the brown alga Undaria pinnatifida and calcareous tubeworm Pomatoceros sp.) were dominant near the entrance to the Sound, where annual temperature cycles are often reduced and salinity concentrations are higher. Generally, biofouling cover decreased with increasing water depth. A large proportion $(48 \%)$ of biofouling biomass scores were categorised as high, equating to $121.2 \pm 20 \mathrm{~g} \mathrm{~m}^{-2}$ (or $16 \%$ ) of long-line for a heavily fouled farm, or $10 \mathrm{t}$ for a typical 3 ha farm. Distributional patterns, such as those identified in this study, could be used by aquaculture industries to better inform the timing and placement of susceptible crop species and production stages (e.g. mussel spat). Refined monitoring methods may also facilitate industry participation in collecting long-term biofouling records.
\end{abstract}

KEY WORDS: Biofouling - Artificial substrate $\cdot$ Community structure $\cdot$ Aquaculture $\cdot$ Mussel $\cdot$ Perna canaliculus

\section{INTRODUCTION}

Marine farm infrastructure is composed of a diverse range of artificial components, including ropes, floats, anchors, cages, nets and rafts (Fitridge et al. 2012). These surfaces, which intercept water flow and consequently larvae in the water column, provide extensive habitat for colonisation by biofouling organisms (Metri

*Corresponding author: ashleigh.watts@niwa.co.nz et al. 2002, McKindsey et al. 2007, Dürr \& Watson 2010, Adams et al. 2011, Fitridge et al. 2012, Antoniadou et al. 2013, Sievers et al. 2013). The accumulation of biofouling is predominantly detrimental for aquaculture industries, reducing revenue and crop growth, and increasing processing and production costs, disease risk, structural fatigue, farm load, and the mechanical handling and maintenance of equip-

() The authors 2015. Open Access under Creative Commons by Attribution Licence. Use, distribution and reproduction are unrestricted. Authors and original publication must be credited. 
ment (Claereboudt et al. 1994, Grant et al. 1998, McKindsey et al. 2009, Fitridge et al. 2012, Fitridge \& Keough 2013, Sievers et al. 2013, Lacoste \& Gaertner-Mazouni 2014). For example, dominant growth of the ringed tubularian Ectopleura larynx in the Norwegian fish farming industry increases the frequency and duration of infrastructure cleaning during peak fouling seasons (Guenther et al. 2009, 2010).

In the mussel aquaculture industry, culture stock provides an ideal and accessible 3-dimensional biofouling surface. The major biofouling groups that colonise mussel shells include sponges, barnacles, spirorids/serpulids and ascidians (Dürr \& Watson 2010), many of which are non-indigenous and have detrimental impacts on the appearance, marketability, growth and condition of crop species. For instance, shell-boring polychaete worms such as Polydora spp. devalue shellfish appearance, reduce hinge stability, disrupt shell formation and increase the vulnerability of shellfish to predation (Che et al. 1996, Lleonart et al. 2003, Silina 2006, Simon et al. 2006, Fitridge et al. 2012, Fitridge \& Keough 2013, Sievers et al. 2014). In addition, increased biomass of the invasive colonial ascidian Didemnum vexillum has been found to displace small, cultured New Zealand green-lipped mussels Perna canaliculus (Fletcher et al. 2013b).

A number of techniques have been employed and are continually being developed to mitigate and control biofouling in the aquaculture sector (Fitridge et al. 2012), including cleaning and replacing equipment, biocidal paints, chemical treatments, heat treatments, physical removal of pest species or exposure of artificial infrastructure to periods of air-drying, high-pressure power washing and fresh or hot water baths (Enright 1993, Chambers et al. 2006, Forrest \& Blakemore 2006, López-Galindo et al. 2010, Carl et al. 2012, Fitridge et al. 2012). Novel antifouling approaches are also being trialled, including 'ecofriendly' antifouling formulations based on natural compounds and novel surface characteristics (Cahill et al. 2013), as well as the development of marine pest biocontrol tools (Atalah et al. 2013). However, the control of biofouling is industry-specific, and effective management requires the development of technologies and methods of application specific to the culture environment. Therefore, control methods in mussel aquaculture predominantly focus on maintaining clean shells through the use of avoidance strategies (Fitridge et al. 2012, Sievers et al. 2014).

While many of the described techniques may be successful in removing soft-bodied biofoulers, some fail to remove or prevent the settlement of several species of barnacles and calcareous tubeworms (Carver et al. 2003, Forrest \& Blakemore 2006, LeBlanc et al. 2007). Their implementation can also have undesirable effects, such as the fragmentation of colonial organisms, which may contribute to their localised spread (Hopkins \& Forrest 2010, Paetzold \& Davidson 2011). In addition, biofouling treatments can increase the intensity of stock stress and mortality (LeBlanc et al. 2007, Antoniadou et al. 2013).

The occurrence and impacts of specific biofouling species on marine farm structures varies spatially (Ceccherelli \& Campo 2002, Thomsen et al. 2006) and temporally (Stæhr et al. 2000, Forrest \& Taylor 2002), including variation in community structure among years (Underwood \& Anderson 1994), locations (Lutz-Collins et al. 2009, Sievers et al. 2014) and depths (Hanson \& Bell 1976, Woods et al. 2012). For example, Woods et al. (2012) and Cronin et al. (1999) found reduced biofouling biomass and less diversity in biofouling communities with increased depth on marine farm structures (mussel long-lines and tuna sea cages). Some biofouling populations also proliferate rapidly and then gradually retreat. This is especially true for taxa such as ascidians, including invasive pest species such as D. vexillum, Ciona intestinalis and Styela clava (Valentine et al. 2007, Forrest et al. 2011, Fletcher et al. 2013a). Consequently, it is imperative that more studies quantify variability in these patterns to improve risk management.

An alternative approach for biofouling management in mussel aquaculture could therefore be to incorporate a more information-based approach, as suggested by Sievers et al. (2014) and Fitridge et al. (2012). Such an approach would involve linking knowledge about site-specific patterns of biofouling development (or predictions of their occurrence) with strategies to avoid specific locations during times of heavy biofouling, or strategies to remove biofouling species. This knowledge could also inform decisions regarding the placement of susceptible crop species and stages of production (e.g. mussel seed stock) within a specific region or water depth.

In New Zealand, Pelorus Sound (located in the Marlborough Sounds) is the major growing region for the mussel farming industry, with approximately 645 farms spread across 5000 ha of farming area (Woods et al. 2012). Despite the value and extent of this area, aside from a few site-specific studies (Woods et al. 2012), our knowledge about the spatial and temporal variation of biofouling organisms associated with these aquaculture farms is limited. Hence, this study had 3 specific objectives: (1) to characterise biofouling on mussel farm long-lines in Pelorus Sound, with 
the expectation that community structure and the relative abundance of pest species would vary across the study region; (2) to investigate the influence of depth on biofouling community structure and species relative abundance, with the expectation that biofouling cover would decrease with increasing depth; and (3) to assess potential mechanisms contributing to biofouling structure by investigating the relationship between biofouling community similarity and distance between marine farms, with the expectation that community similarity would decrease as geographical distance between farms increased.

\section{MATERIALS AND METHODS}

\section{Study region}

Pelorus Sound is located within the Marlborough Sounds, at the northern end of New Zealand's South Island (Fig. 1). It is a $56 \mathrm{~km}$ long, relatively deep (average water depth $40 \mathrm{~m}$ ) and highly indented estuarine system with variable freshwater input from the Kaituna and Pelorus rivers entering at the head of the Sound, as well as oceanic exchange from upwelling waters in Cook Strait (Heath 1974, Woods et al. 2012). There are complex tidal, estuarine and

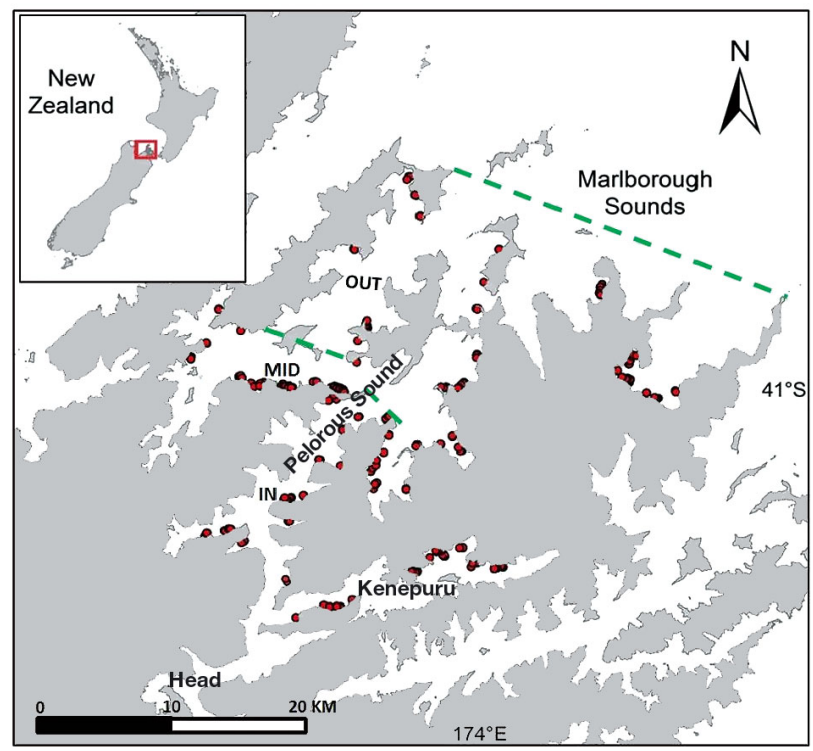

Fig. 1. Marlborough Sounds region, showing the location of commercial green-lipped mussel Perna canaliculus farms sampled in Pelorus Sound (filled red circles), from the inner (IN), middle (MID), and outer (OUT) areas. Dashed green lines: delineation of the 3 areas. The 'head' of the Pelorus Sound and the Kenepuru Sound are indicated. Inset shows the location of the Marlborough Sounds at the northern tip of New Zealand's South Island wind-driven circulation systems in the Pelorus, with mean residence times varying from $21 \mathrm{~d}$ in Pelorus channel to $6 \mathrm{~d}$ in the Kenepuru. Reduced flushing rates and strong stratification have been recorded within the side arms and embayments near the head of Pelorus Sound. Stratification is generally driven by salinity (Heath 1974, Gibbs et al. 1991), with a gradual decrease in mean salinity towards the confluence with Kenepuru Sound (Heath 1982, Broekhuizen et al. 2015) (Fig. 2a,b). Annual mean temperatures are also warmer near the head of Pelorus Sound, although Broekhuizen et al. (2015) recorded seasonal variation in this pattern with cooler winter temperatures and warmer summer temperatures near the head of Pelorus Sound compared to the outer Sound (Fig. 2c,d).

\section{Biofouling characterisation}

In January 2013, a total of 73 commercial greenlipped mussel Perna canaliculus farms were sampled within the inner $(\mathrm{n}=30)$, middle $(\mathrm{n}=26)$ and outer ( $\mathrm{n}=17$ ) Sound (Fig. 1). The 3 area boundaries were set in accordance with previously conducted dispersal studies (Knight et al. 2010), as well as the known environmental gradients and hydrodynamic characteristics in Pelorus Sound (Heath 1974, Gibbs et al. 1991, Broekhuizen et al. 2015). Each mussel farm was considered to be a single replicate within the larger area of interest (inner, middle, outer). Therefore, each mussel farm was randomly selected, and within each farm a random selection of long-line droppers (1-4 per farm; inner $\mathrm{n}=50$, middle $\mathrm{n}=46$, outer $\mathrm{n}=$ 29) were sampled. Mussel farm long-lines were situated between $50-250 \mathrm{~m}$ of the shoreline. Therefore, the inner- and outermost long-lines were excluded to standardise the influence of sampling position. The droppers were lifted from the water column using a winch onboard an industry product-sourcing vessel. Each dropper was systematically photographed (Nikon Coolpix AW100, 16 megapixels) using a $0.4 \times 0.2 \mathrm{~m}$ photoquadrat; 3 images were taken within the surface $3 \mathrm{~m}$ of the dropper ( $0-3 \mathrm{~m}$ of the long-line depth) and 3 within the bottom $3 \mathrm{~m}$ (9-12 or 21-24 m depth, depending on the area's water depth and subsequent length of the looped long-line). To ensure photoquadrats were independent, a $50 \mathrm{~cm}$ gap was left between photoquadrats, and a 6-18 $\mathrm{m}$ gap was left between photoquadrats taken within the 2 depth ranges. Video footage (Sony HDR-XR350VE) was also taken from each mussel long-line dropper that incorporated the areas where photoquadrats were 

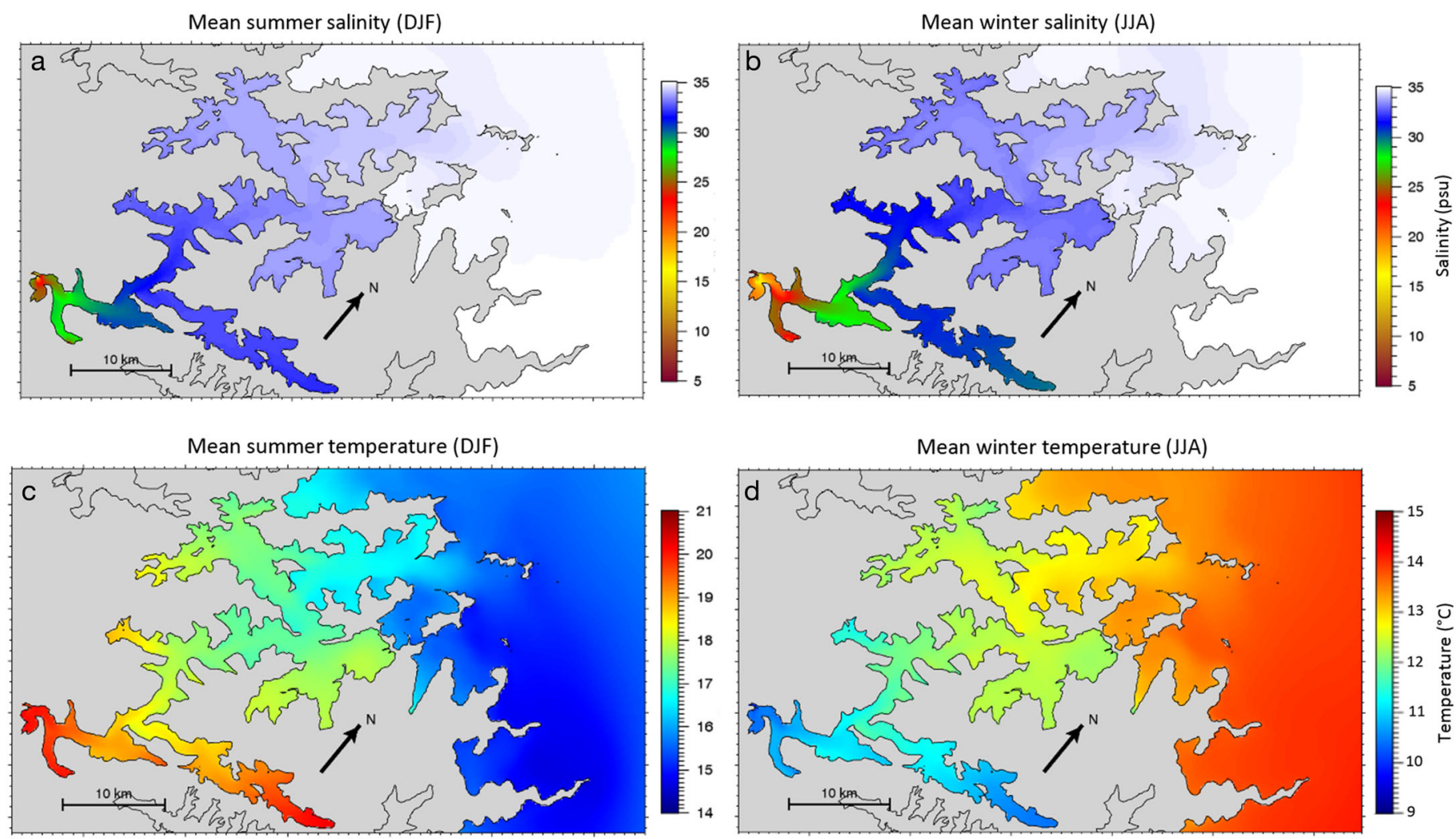

Fig. 2. Summer (DJF: Dec 2012-Jan-Feb 2013) and winter (JJA: Jun-Jul-Aug 2013) mean (a,b) salinity and (c,d) temperatures from a Pelorus Sound model (figure by Mark Hadfield, NIWA). This model was compared with, and matched monthly CTD surveys conducted by NIWA in Pelorus Sound from 2012 to 2014 (see Broekhuizen et al. 2015). Graphs are on a rotated map projection; colour scales represent temperature and salinity ranges and units

taken as well as the remaining long-line dropper length.

The presence of conspicuous biofouling pests (i.e. those with previously documented impacts to aquaculture in New Zealand and overseas) on other farm infrastructure (i.e. backbone ropes, floats, anchor warps) was recorded, and voucher specimens were collected for identification and future reference. In addition, crop line age (at the time of sampling) was obtained from an industry database.

Visual assessments of biofouling biomass and percentage cover of bare rope space (i.e. no crop present) were also recorded from all mussel long-lines across the 3 sampling locations (inner, middle and outer), along with observations of dominant biofouling species (including non-indigenous species). Video footage was used as an extra resource for confirmation of these visual assessments.

During crop-condition assessments, mussel-sourcing staff often estimate and record the presence and extent of biofouling biomass on mussels. Following discussions with these staff, 3 biomass categories were selected and assessed to determine how to reli- ably estimate biomass from visual assessments, and to determine how these contributed to long-line weight. The 3 biomass categories represented low (2dimensional, or small patches of 3-dimensional), medium (largely 3-dimensional, but patchy) and high (extensive cover by 3-dimensional) biofouling. Prior to sampling, the reliability of these visual assessments was verified by removing crop and fouling biomass from five $0.4 \mathrm{~m}$ sections of crop rope for each of the 3 biomass categories. These sections were spread across the 3 sampling locations and included 2 biomass sections from the inner area, 2 from the middle and 1 from the outer area for the low and high biofouling biomass categories, as well as 1 sample from the inner, 3 from the middle and 1 from the outer area for the medium biofouling biomass category. Samples were individually labelled and transported, cooled $\left(<10^{\circ} \mathrm{C}\right)$, to the Cawthron Institute laboratory (Nelson, New Zealand) within $12 \mathrm{~h}$ of collection. In the laboratory, the total wet weight of bivalves with biofouling was measured for each sample. Also, the wet weight of biofouling from a subset of 20 greenlipped mussels was obtained from each sample. 
Photoquadrat images were cropped in Google Picasa v.3.9, and poor quality images were removed from analyses. The percent cover of biofouling taxa (identifiable and unidentifiable), crop and rope longline beneath 75 randomly stratified points were determined using the Coral Point Count with excel extensions (CPCe) (Kohler \& Gill 2006). The selection of 75 points per image was determined during preliminary precision and accuracy analyses, which identified whether point count analyses reflected the 'true' percent cover of taxa, represented by arealength analyses. Variation in precision, accuracy and time efficiency using a variety of points per image in CPCe were also assessed (Watts 2014). Biofouling organisms were identified to the highest taxonomic resolution possible from photographs. For certain groups, such as filamentous algae and ascidians, identification was restricted to higher level descriptions. Voucher species were used to assist with identification, and in some cases verification was provided by taxonomists.

\section{Statistical analyses}

Comparison of visual and photographic assessments

To determine the efficiency of using photographs to capture biofouling taxa compared to visual estimates of presence/absence for dominant biofouling taxa, the 2 datasets from these methods were compared. Percent cover data from photoquadrats were transformed into presence/absence data using PRIMER v.6 with PERMANOVA add-on (Anderson 2001a, Clarke \& Gorley 2006, Anderson et al. 2007). The percent of records where photoquadrats recorded taxa as present were then compared to the percent of records where visual estimates did not observe these taxa (and vice versa), using $R$ v.3.0.2 ( $R$ Core Team 2013). The mean biomass measured from the 3 biomass categories was also compared using a univariate permutational analysis of variance.

\section{Multivariate analysis}

Changes in community structure among areas and depths were investigated using distance-based permutational multivariate analysis of variance (PERM-

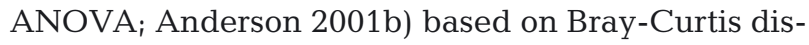
similarities of the square-root transformed data (Bray \& Curtis 1957). A square-root transformation was selected over a more severe transformation (e.g. fourth root or presence/absence transformation) where rare species contributed disproportionately more to the analyses (Anderson 2001a).

The experimental design consisted of 4 factors and 1 covariate: (1) area (fixed with 3 levels: inner, middle and outer), (2) depth (fixed with 2 levels: surface and bottom), (3) farm (random with 73 levels, nested within area), and (4) long-line droppers (random with 125 levels, nested within farm), with crop age (i.e. months since long-lines were first seeded) included as a covariate. Crop age ranged from 1 to 67 mo and varied across farms within each area. Interactions between the covariate (age) and the fixed and random variables were excluded from analyses, as the influence of crop age was not a key objective of this study and was not consistently sampled. Therefore, excluding these terms prevented over-parameterization of the model. Each term was tested using 4999 permutations and a Type I SS (sums of squares) (Anderson 2001b, Anderson \& Ter Braak 2003). Significant terms were then investigated using a posteriori pairwise comparisons with the PERMANOVA $t$-statistic and 999 permutations. Multivariate variance components expressed as square-root variance components (i.e. converting values to percentages of Bray-Curtis dissimilarity) were calculated and compared for each term in the analysis (Underwood \& Petraitis 1993, Anderson et al. 2007). The distribution of the covariate (crop age) was skewed, and as covariates used in PERMANOVA are expected to show approximately symmetric distributions that are roughly normal, was square-root transformed (Anderson et al. 2007). Bare space and green-lipped mussel percent cover were removed from analyses to ensure similarity was not driven by substrate. In addition, sub-canopy species (i.e. those not visible beneath biofouling) could not be included in the analyses due to the sampling method used in this study (photoquadrats).

A permutational analysis of multivariate dispersions (PERMDISP) was also used, followed by pairwise comparisons, to test for differences in dispersion among areas and between depths using 4999 permutations. In addition, a similarity percentage analysis (SIMPER; Clarke 1993) was conducted to identify the contribution of each species (or taxon) to observed community dissimilarities (cut-off set to $80 \%$ ) between significant factors. Taxa were considered important if their contribution to percentage dissimilarity was $\geq 6 \%$. The ratio of the average dissimilarity and standard deviation (Diss/SD) was used to indicate the consistency with which a given species contributed to dissimilarity (Clarke 1993, Clarke \& Gor- 
ley 2006); values $\geq 1.5$ indicated a high degree of consistency. Differences in community structure among areas were visualised through a principal coordinates analysis (PCO; Gower 1966). Taxa that consistently discriminated between significant terms and had a correlation $>0.3$ with the PCO axes were displayed as vectors in the PCO plot. Variability in the cover of contributing taxa were assessed using separate 2-way univariate permutational analysis of variance tests (ANOVAs) on the square-root transformed variables (Anderson 2001b). To account for multiple comparisons and control alpha inflation, a False Discovery Rate (FDR) correction was applied $(\mathrm{n}=8, \mathrm{p}<$ 0.02 represented significance) (Benjamini \& Yekutieli 2001, Narum 2006). Statistical analyses were done using PRIMER v.6 with PERMANOVA add-on (Anderson 2001a, Clarke \& Gorley 2006, Anderson et al. 2007).

\section{Spatial correlation of biofouling communities}

Alongside information on the spatial structure of ecological communities, distance approaches have proven effective and informative for gauging the spatial turnover of communities (Soininen et al. 2007, Morlon et al. 2008). Species spatial turnover, or beta diversity, often induces reduced community similarity with increasing geographic distance, known as the distance-decay relationship (Morlon et al. 2008). Distance-decay relationships were investigated using Partial Mantel tests calculated in the 'vegan' community ecology package (Oksanen et al. 2011) in $\mathrm{R}$ (R Core Team 2013).

We determined the relationship between community structure and geographic distance among farms using a distance-decay analysis between the Bray-Curtis dissimilarity matrix of the community structure data (square-root transformed) and a Euclidean distance matrix of the geographic distances between all farms. The Wisconsin double standardisation method, which improves the gradient detection of dissimilarity measures (Oksanen 2011), was used alongside Bray-Curtis dissimilarity to generate the community structure matrix (Oksanen 1983, Legendre \& Gallagher 2001, Anderson 2006). As pairwise similarity values and distances were not truly independent in a statistical sense, partial Mantel statistics were estimated using the 'matrix permutation' method with 9999 permutations. Linear regression was used to describe the relationship between dissimilarity values and geographical distance.

\section{RESULTS \\ Comparison of visual and photographic assessments}

When comparing species cover attained from photoquadrats with that from visual estimates, it was evident that visual estimation alone was not a reliable method for determining biofouling species on mussel long-line droppers. Fifty percent of the records attained from photoquadrats detected taxa as being present when visual estimates recorded them as absent, while only $2 \%$ of the records gained by visual estimates recorded taxa as present when photoquadrats did not. Photoquadrats therefore provide a more reliable representation of biofouling cover on long-line droppers.

\section{Community structure and patterns in the cover of problematic biofoulers}

A total of 86 biofouling taxa were identified occupying vacant space on crop long-lines, or occurring epibiotically on mussel shells and other biofouling organisms (Table 1). Overall, communities were dominated by red filamentous algae and the Asian kelp Undaria pinnatifida (macroalgae), the blue mussel Mytilus galloprovincialis, hydroids, bryozoans and ascidians (Fig. 3). Less abundant taxa included sponges, anemones and mobile taxa, such as amphipods, isopods, sea cucumbers and crabs (Fig. 3). Biofouling cover was significantly greater near the surface of mussel long-lines $\left(t_{1}=5.75, \mathrm{p}<0.01\right)$.

\section{Community composition}

Patterns of variation in community structure are depicted in the PCO plot (Fig. 4a), showing a clustering and separation of communities located in different areas (specifically the inner area from the middle and outer areas; Fig. 4a), and at different depths (Fig. 4b). These patterns were reflected in PERMANOVA analyses, which indicated a significant interactive effect of area and depth on the structure of biofouling communities (depth $\times$ area effect, $\mathrm{p}<$ 0.001; Table 2). Pairwise comparisons revealed that community structure differed significantly between the 2 depths, but this effect varied among all areas (for all pairwise comparisons, p < 0.001; Table 2). Average percent similarity in community structure was lowest between inner and outer areas, across 
Table 1. Taxa and species occurring in biofouling communities on green-lipped mussel Perna canaliculus long-lines across Pelorus Sound, New Zealand

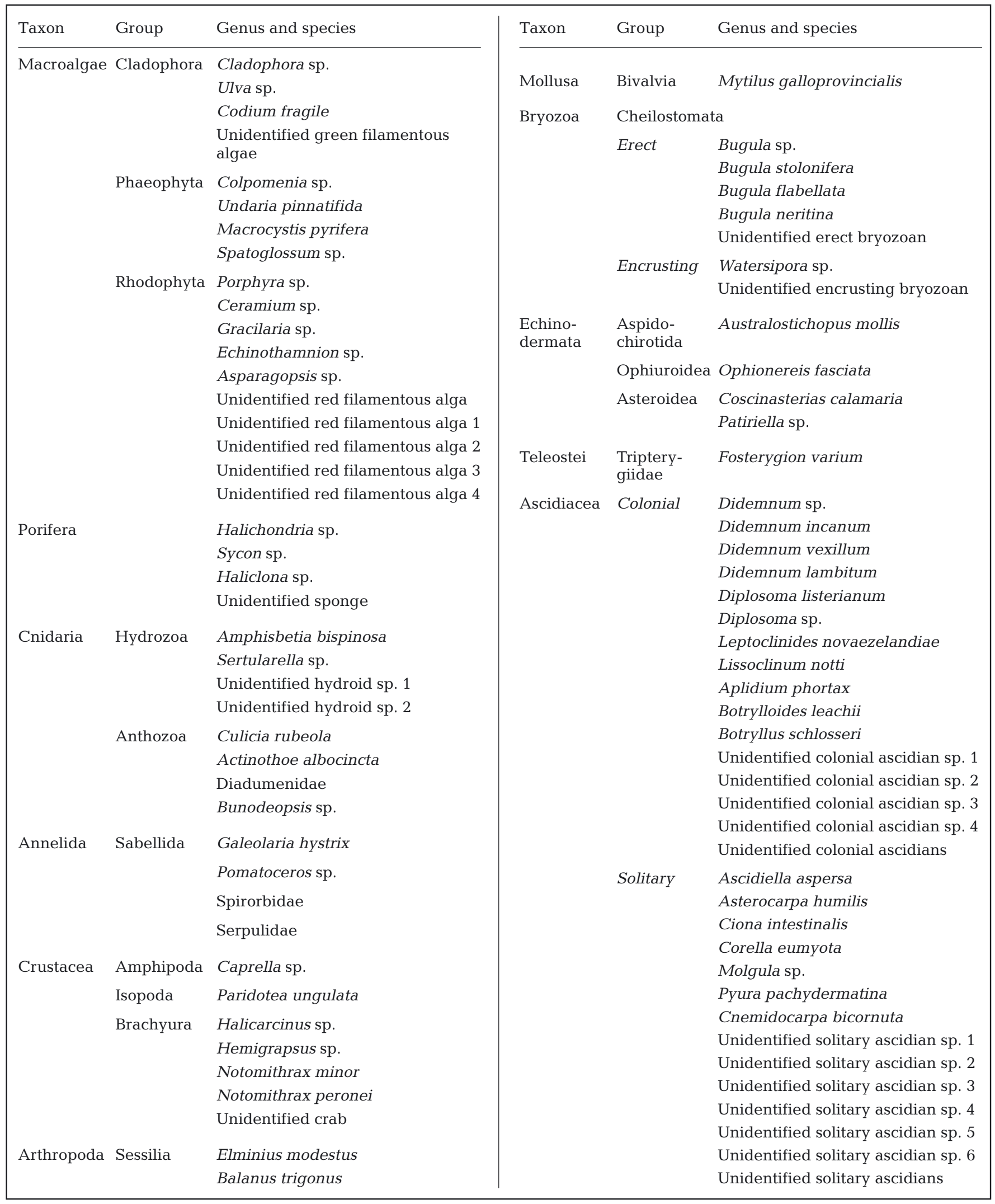




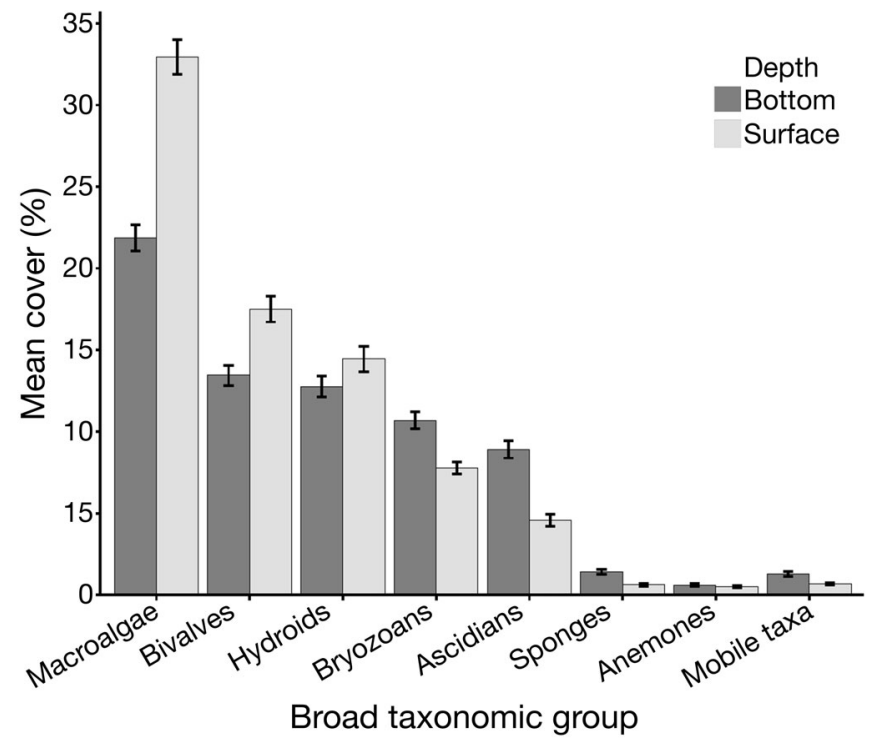

Fig. 3. Mean $( \pm \mathrm{SE})$ percentage cover of broad taxonomic groups of biofouling organisms found on green-lipped mussel Perna canaliculus long-line droppers. Results are shown across all areas sampled in Pelorus Sound, in accordance with depth

depths (Table 2). Furthermore, the effect of depth on community structure significantly varied between long-lines: depth $\times$ long-line (Farm[Area]), $\mathrm{p}<0.001$ (Table 2). There was also a significant positive relationship between crop age and community structure (age, p $<0.001$; Table 2). The greatest component of variation for biofouling community structure occurred at the lowest spatial scale (the residual, $28 \%$ ), followed by between farms within areas (Table 2). Moderate variability was observed among areas, and the lowest variance component was estimated across crop ages (Table 2).

The percentage cover of several pest species varied with area and depth across Pelorus Sound. There was a trend for high cover of hydroid species Amphisbetia bispinosa and macroalgae, including Cladophora sp., $U$. pinnatifida and Colpomenia sp. near the entrance of Pelorus Sound, within the surface $3 \mathrm{~m}$ of sampled long-line droppers. There was also a trend for high cover of the calcareous tubeworm Pomatoceros sp. near the entrance of Pelorus Sound, but within the bottom $3 \mathrm{~m}$. The cover of $M$. galloprovincialis tended to be highest in the surface 3 $\mathrm{m}$ of long-line droppers in the middle of Pelorus Sound, and the colonial and solitary ascidians Didemnum vexillum and Ciona intestinalis (respectively) had a tendency for high cover near the head of Pelorus Sound, also within the surface $3 \mathrm{~m}$.
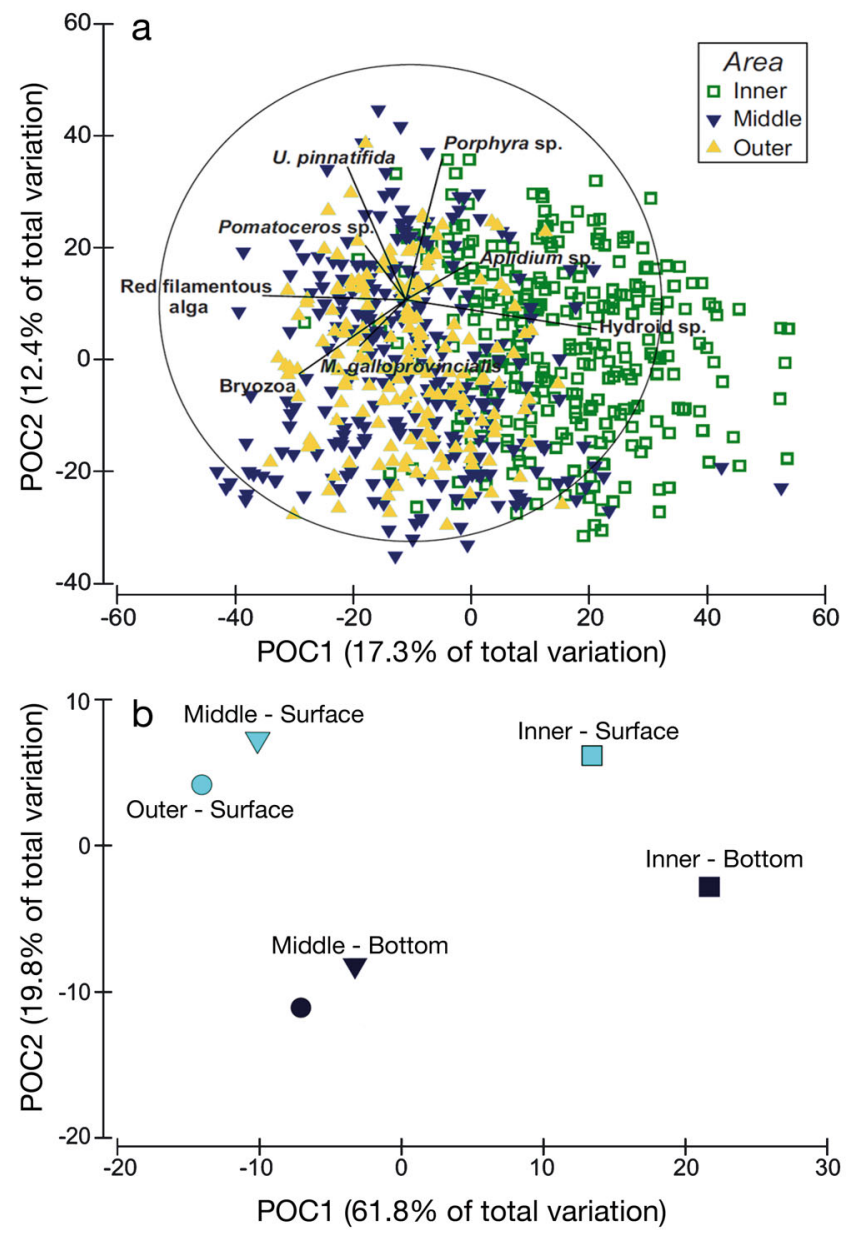

Fig. 4. Principal coordinate analysis (PCO) plots on the basis of Bray-Curtis dissimilarities of the square-root transformed (a) percent cover data of biofouling communities across the inner (square), middle (upside-down triangle) and outer (upwards triangle) Sound, along with the species contributing to differences in biofouling assemblages (correlation $>0.3$ ), and (b) across the inner (square), middle (upside-down triangle) and outer (circle) Sound, in association with depth. Distances among centroids for all photoquadrat results across the inner, middle and outer Sound (with depth, represented by symbol shading: light blue symbols = surface $3 \mathrm{~m}$ and dark blue = bottom $3 \mathrm{~m}$ ) are presented in (b)

SIMPER analysis revealed that 6 taxa (red filamentous alga, an unidentified hydroid, encrusting bryozoans, U. pinnatifida, Porphyra sp. and M. galloprovincialis) contributed consistently to the community dissimilarities between areas and depths (Table 3); however, their contributions were relatively low (6 to $11 \%)$. The largest average dissimilarity was between fouling in the bottom $3 \mathrm{~m}$ of long-line droppers in the inner Sound and fouling in the surface $3 \mathrm{~m}$ in the outer Sound $(70.17 \%$; Table 3$)$. Patterns revealed by the SIMPER analysis were confirmed by univariate permutational ANOVAs on the cover of the most 
Table 2. Multivariate PERMANOVA results based on Bray-Curtis dissimilarities for spatial differences in community structure (squareroot transformed) at the scales of area and depth, with age as a covariate. Pairwise comparisons for the depth $\times$ area interaction effect, within factor area, are included. Estimates of multivariate variation (variation \%), the estimated sizes of average similarities between areas (AS), mean sums of squares (MS), F-statistics $(F)$ and pairwise $t$-statistics $(t)$ are also included. ${ }^{*} \mathrm{p}<0.05 ;{ }^{* *} \mathrm{p}<0.01 ;{ }^{* * *} \mathrm{p}<0.001$

\begin{tabular}{|c|c|c|c|c|}
\hline Source of variation & df & MS & $F$ & $\begin{array}{c}\text { Variation } \\
(\%)\end{array}$ \\
\hline Age & 1 & 24058 & $3.95^{* * *}$ & 5 \\
\hline Depth & 1 & 45716 & $19.35^{* * *}$ & 11 \\
\hline Area & 2 & 74469 & $9.58^{* * *}$ & 16 \\
\hline Farm(Area) & 70 & 6933 & $2.70^{* * *}$ & 21 \\
\hline Depth $\times$ Area & 2 & 7411 & $3.19^{* * *}$ & 6 \\
\hline Long-line(Farm[Area]) & 52 & 2531 & $3.31^{* * *}$ & 17 \\
\hline Depth $\times$ Farm(Area) & 70 & 2108 & $1.57^{* * *}$ & 12 \\
\hline Depth $\times$ Long-line(Farm[Area]) & 52 & 1346 & $1.76^{* * *}$ & 14 \\
\hline Residuals & 511 & 766 & & 28 \\
\hline \multicolumn{5}{|l|}{ Pairwise comparisons } \\
\hline Groups & & $t$ & AS (\%) & \\
\hline \multicolumn{5}{|l|}{ Surface depth } \\
\hline Inner-Middle & & $3.19^{* * *}$ & 41 & \\
\hline Inner-Outer & & $3.06^{* * *}$ & 36 & \\
\hline Middle-Outer & & $1.56^{* * *}$ & 43 & \\
\hline \multicolumn{5}{|l|}{ Bottom depth } \\
\hline Inner-Middle & & $3.48^{* * *}$ & 37 & \\
\hline Inner-Outer & & $3.13^{* * *}$ & 33 & \\
\hline Middle-Outer & & $1.82^{* * *}$ & 43 & \\
\hline
\end{tabular}

prominent taxa contributing to dissimilarities, and on taxa with a high correlation (>0.3) with the PERMANOVA PCO axis. Depth had a significant effect on the cover of encrusting bryozoans, an unidentified hydroid and $M$. galloprovincialis, which was area dependent (area $\times$ depth effect, $\mathrm{p}<0.01$ ). Encrusting bryozoans tended to have high cover within the bottom $3 \mathrm{~m}$ of mussel long-line droppers, in the middle and outer areas (Fig. 5). The unidentified hydroid and M. galloprovincialis typically had high cover at the surface of mussel long-line droppers in the inner and middle areas, respectively (Fig. 5). Depth and area also had a significant effect on the cover of red filamentous alga and U. pinnatifida, but there was no interaction between these factors (depth effect, $\mathrm{p}<$ 0.01 ; area effect, $\mathrm{p}<0.01$ ). Red filamentous alga and $U$. pinnatifida had higher cover within the outer area (Fig. 5). Area alone had a significant effect on the cover of Porphyra sp. (area effect, p < 0.001), with a tendency for high cover in the inner area (Fig. 5). Univariate PERMANOVA tests also revealed that the cover of Aplidium sp. and Pomatoceros sp., which had a high correlation ( $>0.3$ ) with the PERMANOVA PCO axis (Fig. 4a), significantly differed with depth and across areas (area $\times$ depth effect, p < 0.001). The cover of Aplidium sp. and Pomatoceros sp. tended to be highest at the bottom depth, in the inner and outer areas, respectively (Fig. 5).

PERMDISP analyses showed significant differences in multivariate dispersion between areas, which varied with depth (area $\times$ depth effect, $\mathrm{p}<0.001$; Table 4). Pairwise comparisons revealed that this was due to significantly greater dispersion near the bottom of the mussel long-lines within the inner area of Pelorus Sound compared to the surface of the mussel long-lines $\left(t_{1}=4.444, \mathrm{p}<0.001\right.$; Table 4$)$.

\section{Spatial correlation between fouling communities}

A relatively weak but significant positive relationship was detected between the geographical distance of sampled mussel farms across Pelorus Sound and the dissimilarity in biofouling community structure $(b=0.35, \mathrm{r}=$ $0.40, \mathrm{p}=0.03)$. Specifically, dissimilarity in the structure of biofouling assemblages increased, with a steep slope, with geographical distance (Fig. 6).

\section{Biofouling levels and biomass}

There were no significant differences between the 3 categories used to assess biofouling biomass ( $\mathrm{p}>$ 0.05). Although there was an increase in biomass weights (kg) associated with an increase in the category of biomass cover (low, medium to high) (Fig. 7a), high variation and overlap in the biomass categories indicate the need to refine such a method before it could be used reliably to accurately predict biomass levels. However, for the purpose of this study it was considered appropriate to provide course estimates of fouling biomass levels within the study system.

A large proportion of observed biomass scores were high $(16 \%$ of the total wet weight across sampled sections) and predominantly occurred in the outer Pelorus Sound (Fig. 7b), while the proportion of low and medium biomass scores were lower (5 and $12 \%$ respectively), and primarily occurred in the middle and inner areas (Fig. 7b). Sections of culture rope $(0.4 \mathrm{~m})$ visually assessed as having 'low' biofouling biomass had on average $57.8 \pm 14.5 \mathrm{~g} \mathrm{~m}^{-2}(43-72 \mathrm{~g}$ $\mathrm{m}^{-2}$ ) of biofouling (wet weight), whereas 'medium' 
Table 3. Similarity percentage analysis (SIMPER) summary showing taxa with the highest percent contribution (reflected in the taxa order) towards the dissimilarity between areas, within different depths across Pelorus Sound (IB: inner bottom; IS: inner surface; MB: middle bottom; MS: middle surface; OB: outer bottom; OS: outer surface). Contributing taxa were red alga (red filamentous alga), Hydroid (hydroid species-1), Bryozoa (encrusting bryozoans), Porphyra (Porphyra sp.), Mytilus (Mytilus galloprovincialis) and Undaria (Undaria pinnatifida). Taxa \% contribution was $\geq 6 \%$. All taxa listed consistently contributed (\%) to group dissimilarity; (-) no data

\begin{tabular}{|c|c|c|c|c|c|}
\hline & IB & IS & MS & $\mathrm{MB}$ & OS \\
\hline OB & $\begin{array}{l}\text { Avg. diss.: } 67.01 \\
\text { Red alga } \\
\text { Hydroid } \\
\text { Bryozoa } \\
\text { Porphyra }\end{array}$ & $\begin{array}{l}\text { Avg. diss.: } 62.63 \\
\text { Hydroid } \\
\text { Bryozoa } \\
\text { Red alga } \\
\text { Porphyra }\end{array}$ & $\begin{array}{l}\text { Avg. diss.: } 59.26 \\
\text { Mytilus } \\
\text { Red alga } \\
\text { Bryozoa } \\
\text { Hydroid }\end{array}$ & $\begin{array}{l}\text { Avg. diss. : } 57.47 \\
\text { Bryozoa } \\
\text { Red alga } \\
\text { Hydroid } \\
\text { Porphyra }\end{array}$ & $\begin{array}{l}\text { Avg. diss.: } 60.91 \\
\text { Red alga } \\
\text { Bryozoa } \\
\text { Hydroid } \\
\text { - }\end{array}$ \\
\hline OS & $\begin{array}{l}\text { Avg. diss.: } 70.17 \\
\text { Red alga } \\
\text { Hydroid } \\
\text { Porphyra } \\
\text { Bryozoa } \\
\text { Undaria }\end{array}$ & $\begin{array}{l}\text { Avg. diss.: } 63.63 \\
\text { Hydroid } \\
\text { Red alga } \\
\text { Porphyra } \\
\text { Bryozoa } \\
\text { Undaria }\end{array}$ & $\begin{array}{l}\text { Avg. diss.: } 56.98 \\
\text { Mytilus } \\
\text { Red alga } \\
\text { Hydroid } \\
\text { Bryozoa } \\
-\end{array}$ & $\begin{array}{l}\text { Avg. diss.: } 60.02 \\
\text { Red alga } \\
\text { Hydroid } \\
\text { Bryozoa } \\
- \\
-\end{array}$ & \\
\hline MB & $\begin{array}{l}\text { Avg. diss.: } 63.48 \\
\text { Hydroid } \\
\text { Bryozoa } \\
\text { Red alga } \\
\text { Porphyra }\end{array}$ & $\begin{array}{l}\text { Avg. diss.: } 59.21 \\
\text { Hydroid } \\
\text { Bryozoa } \\
\text { Porphyra } \\
-\end{array}$ & $\begin{array}{l}\text { Avg. diss.: } 55.57 \\
\text { Mytilus } \\
\text { Porphyra } \\
\text { Hydroid } \\
\text { Bryozoa }\end{array}$ & & \\
\hline MS & $\begin{array}{l}\text { Avg. diss.: } 66.59 \\
\text { Red alga } \\
\text { Hydroid } \\
\text { Mytilus } \\
\text { Porphyra } \\
\text { Bryozoa }\end{array}$ & $\begin{array}{l}\text { Avg. diss.: } 59.10 \\
\text { Hydroid } \\
\text { Mytilus } \\
\text { Porphyra } \\
\text { Bryozoa } \\
-\end{array}$ & & & \\
\hline IS & $\begin{array}{l}\text { Avg. diss.: } 60.14 \\
\text { Porphyra } \\
\text { Bryozoa } \\
\text { Red alga }\end{array}$ & & & & \\
\hline
\end{tabular}

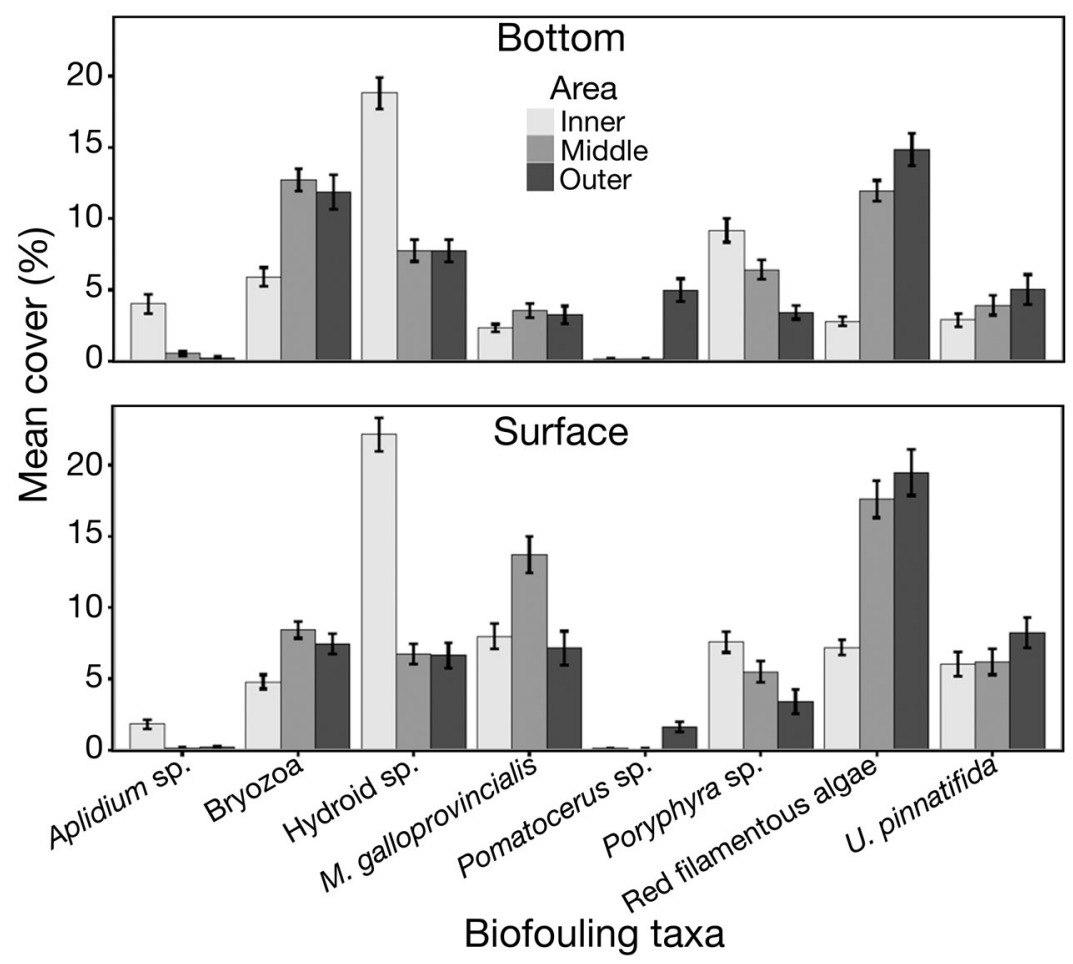

Fig. 5. Similarity percentage (SIMPER) analysis results for the mean $( \pm \mathrm{SE})$ percent cover of taxa contributing to dissimilarities between areas, at different depths across Pelorus Sound. The highest contributing taxa were red filamentous algae, Hydroid sp. (an unidentified hydroid species), Bryozoa (encrusting bryozoans), Porphyra sp., Mytilus galloprovincialis and Undaria pinnatifida. The average abundance of taxa with a correlation >0.3 included Aplidium sp. and Pomatoceros sp., and sp. refers to a single species 
Table 4. Differences in multivariate dispersion (PERMDISP) of the depth $\times$ area interaction effect, with the associated pairwise comparisons for dispersion among and within areas, across depths. Analyses were based on Bray-Curtis dissimilarities and data were square-root transformed. ${ }^{*} \mathrm{p}<0.05$;

$$
{ }^{* *} \mathrm{p}<0.01 ;{ }^{* * *} \mathrm{p}<0.001
$$

\begin{tabular}{|ll|}
\hline Source of variation & $F$ \\
\hline Depth × Area & $11.587^{* * *}$ \\
Pairwise comparisons & \\
Groups & $t$ \\
\hline Bottom Inner-Surface Inner & $4.44^{* * *}$ \\
Bottom Inner-Surface Middle & $6.26^{* * *}$ \\
Bottom Inner-Bottom Middle & $6.28^{* * *}$ \\
Bottom Inner-Bottom Outer & $2.24^{*}$ \\
Bottom Inner-Surface Outer & 1.75 \\
Surface Inner-Surface Middle & 1.84 \\
Surface Inner-Bottom Middle & 1.70 \\
Surface Inner-Bottom Outer & 1.74 \\
Surface Inner-Surface Outer & 1.94 \\
Surface Middle-Bottom Middle & 0.21 \\
Surface Middle-Bottom Outer & $3.39^{* * *}$ \\
Surface Middle-Surface Outer & $3.47^{* * *}$ \\
Bottom Middle-Bottom Outer & $3.36^{* * *}$ \\
Bottom Middle-Surface Outer & $3.44^{* * *}$ \\
Bottom Outer-Surface Outer & 0.3 \\
\hline
\end{tabular}

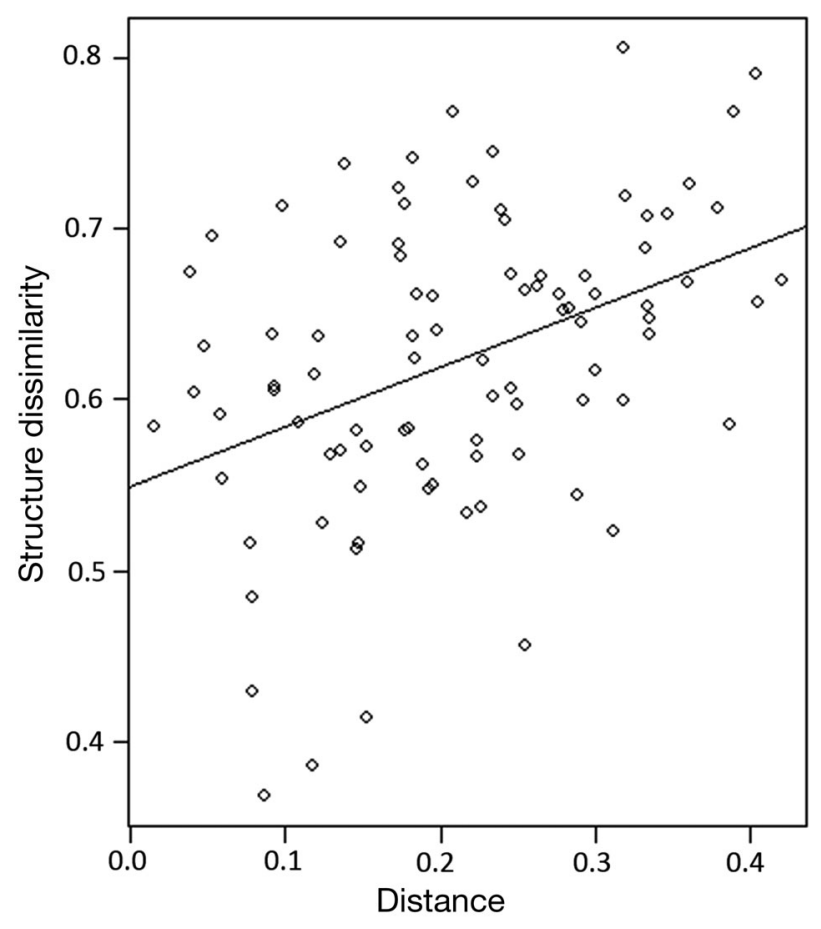

Fig. 6. Distance-decay relationship for the Bray-Curtis matrix of biofouling community dissimilarities against the Euclidean matrix of the geographic distances between sampled marine farms
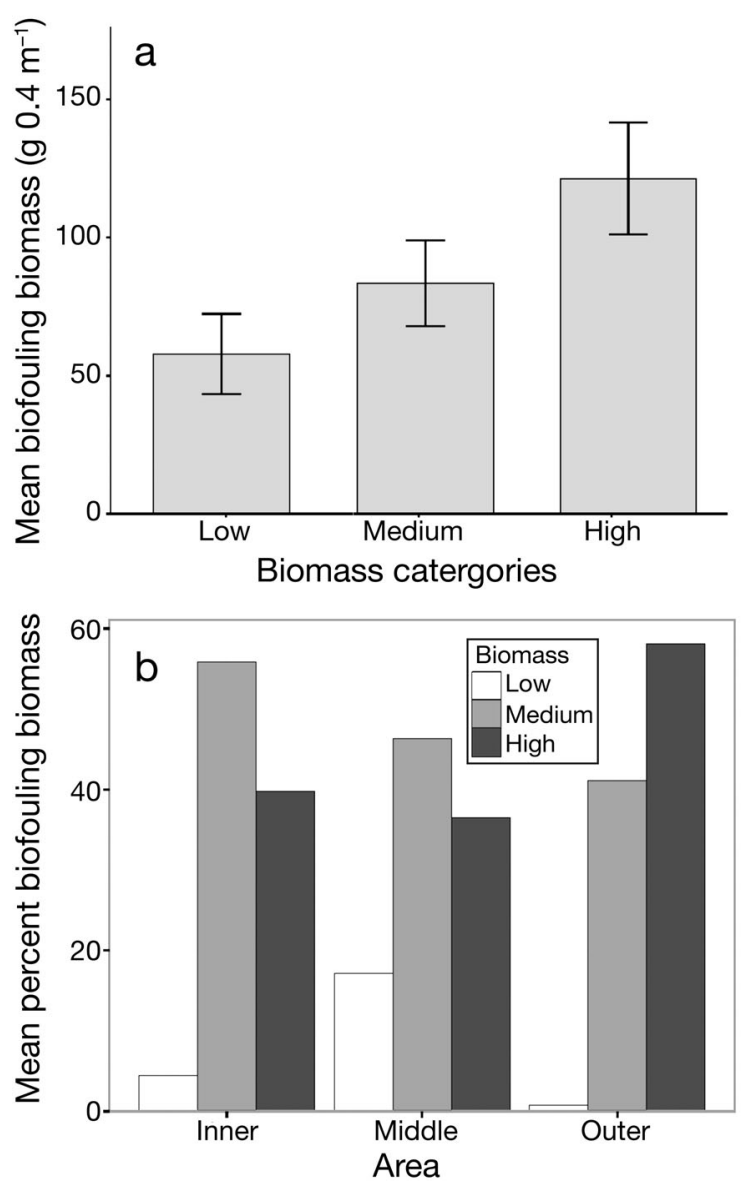

Fig. 7. Mean $( \pm \mathrm{SE})$ biofouling biomass $\left(\mathrm{g} 0.4 \mathrm{~m}^{-1}\right)$ of samples taken to represent (a) pre-set biofouling biomass categories (low, medium and high), and (b) the mean percent occurrence of low, medium and high biofouling biomass categories across the 3 study areas (inner, middle and outer)

and 'high' biomass samples had on average $83.8 \pm$ $15.5 \mathrm{~g} \mathrm{~m}^{-2}\left(68-99 \mathrm{~g} \mathrm{~m}^{-2}\right)$ and $121.2 \pm 20 \mathrm{~g} \mathrm{~m}^{-2}(100-$ $140 \mathrm{~g} \mathrm{~m}^{-2}$ ) of biofouling, respectively.

\section{DISCUSSION}

\section{Patterns of spatial variation in biofouling communities}

This study demonstrated that mussel farm longline droppers in Pelorus Sound support diverse biofouling communities that are spatially variable. A total of 86 distinct taxa were identified, with biofouling cover dominated by macroalgae and suspensionfeeders ( $>60 \%$ of the total cover) such as other bivalves (specifically blue mussels), hydroids, bryozoans and ascidians. Epibenthic communities are generally composed of suspension-feeders and macroalgae, al- 
though this is dependent on water depth and location (Cook et al. 2006). Suspension-feeders are recognised for substantially contributing to the overall biomass of biofouling communities on artificial structures (Lesser et al. 1992, Cronin et al. 1999, Howes et al. 2007, Fitridge et al. 2012). Therefore, these findings are not unexpected, and a dominance of macroalgae and suspension-feeders within biofouling communities have been found on other marine farms, including oyster cultures and tuna farms (Cronin et al. 1999, Mazouni et al. 2001).

The structure of biofouling communities became less similar with increasing geographical distance between sampled mussel farms, making this study the first known, documented account of distancedecay in biofouling communities associated with artificial structures. The slope of the relationship between distance and community similarity in this study was similar to those recorded for intertidal sessile assemblages, but greater than those documented for marine fish communities (Oliva \& Teresa 2005, Tsujino et al. 2010). This contrast makes sense given that the rate of decline of similarity would be greater for organisms with a lower dispersal potential (e.g. ascidian species with a short-lived larval stage or intertidal algae with limited dispersal ranges) in open and continuous marine systems, compared to mobile organisms (Soininen et al. 2007, Tsujino et al. 2010). Furthermore, smaller organisms, which respond more intensively to fine scale environmental variation due to their shorter generation times, may have lower similarity at small distances (Gillooly et al. 2002, Tsujino et al. 2010).

Variation in biofouling communities along Pelorus Sound showed a prominence of known problematic species within the surface depths near the Sound entrance. Biofouling cover was greater within the surface $3 \mathrm{~m}$ of mussel long-line droppers, with macroalgae and sessile filter-feeders dominating these communities; a pattern that was expected given that light, nutrients and oxygen are not a limiting resource in surface waters. This finding is also in agreement with other reports of decreased biofouling biomass and diversity with increasing water depths (Cronin et al. 1999, Braithwaite et al. 2007, Guenther et al. 2010, Fitridge et al. 2012).

Mussel farms near the entrance of the Sound are located within deep, exposed areas, with strong winds from the north and north-west generating high energy storm waves and promoting extensive coastal erosion (Mcintosh 1958). In contrast, mussel farms near the head of Pelorus Sound are in shallower, sheltered areas, experiencing low wave action and periods of reduced or stagnant water flow, which may induce warmer summer temperatures (Gibbs et al. 1991). Furthermore, episodic storm events can generate high freshwater inputs from the Pelorus and Kaituna rivers into areas near the head of Pelorus Sound (Gibbs et al. 1991, Broekhuizen et al. 2015). Differential cover of certain biofouling taxa and associated differences in community structure found in this study could therefore be a reflection of tolerance to local environmental conditions. For example, Undaria pinnatifida is well adapted for life on exposed coastlines, maintaining firm attachment from its holdfast (Curiel et al. 1998, Russell et al. 2008, Nelson 2013). Nanba et al. (2011) found that $U$. pinnatifida sporophytes grown in exposed sites attained larger sizes and had faster growth rates compared to those grown in sheltered sites in Japan. Similarly, the firm attachment of calcareous tubeworms to hard substrate by cementational adhesion makes them well adapted for high wave energy environments (Moate 1985, Callow \& Callow 2002, Bromley \& Heinberg 2006). In contrast, some ascidians such as Ciona intestinalis are more commonly found fouling sheltered habitats, as hydrodynamic processes in exposed areas preclude successful larval settlement (Howes et al. 2007). Furthermore, while it has been documented that ascidians perform best at salinities above 25 PSU and are rarely tolerant of brackish conditions (Lambert 2005), some may be well adapted to fluctuations in ion concentrations. For example, in laboratory experiments Didemnum vexillum showed higher growth rates and survival under low salinities, ranging from 10 to 20 PSU (Gröner et al. 2011).

A number of important problematic pests were identified on mussel long-line droppers in this study, including ascidians (C. intestinalis and $D$. vexillum), macroalgae (U. pinnatifida, Cladophora sp. and Colpomenia sp.), tube-building polychaetes (Pomatoceros sp.), blue mussels (Mytilus galloprovincialis), and the hydroid Amphisbetia bispinosa. These species have had, or currently have, detrimental impacts on commercial industries in New Zealand and overseas. For example, A. bispinosa has been problematic for mussel cultures in the south Hauraki Gulf, adding weight that can enhance crop loss, and damaging shells, reducing their aesthetic value (Heasman \& de Zwart 2004). Similarly, C. intestinalis has become a serious biofouling problem for many shellfish operations in Scotland (Karayucel 1997), South Africa (Hecht \& Heasman 1999), Chile (Uribe \& Etchepare 2002) and eastern Canada (Cayer et al. 1999). 
In support of previous work (Woods et al. 2012), biofouling biomass associated with communities on mussel farms in this study appear to substantially contribute to long-line wet weight. In New Zealand, a typical 3 ha mussel farm would have 9 backbone ropes, each measuring $110 \mathrm{~m}$, and supporting a 3750 m crop long-line (Marine Farming Association pers. comm.). Based on our limited assessment, if biofouling was categorised as low across the entire farm, this would extrapolate to approximately $5 \mathrm{t}$ of biofouling biomass along crop long-lines. Similarly, biofouling biomass would be expected to reach 7 and $10 \mathrm{t}$ for farms categorised as having medium and high biomass, respectively. This weight has important implications for the service lifetime, maintenance and costs of aquaculture buoyancy and anchoring systems associated with these marine farms, and is especially important for farms located in the outer Pelorus Sound, where high biofouling biomass categories were predominantly recorded.

\section{Improved biofouling management opportunities}

Distributional, site-specific patterns of biofouling observed in Pelorus Sound could be used by aquaculture managers to identify areas where dominant biofouling pests are either absent or less prolific. This is particularly relevant for culture species or production stages that are more susceptible to biofouling (Fitridge \& Keough 2013, Sievers et al. 2014). For example, if spat holding areas were placed away from the entrance of Pelorus Sound in deeper waters, this may avoid high levels of biofouling biomass and heavy settlement by notoriously detrimental species such as the brown alga Colpomenia sp., which create problems for spat retention in the Marlborough Sounds, or the hydroid species A. bispinosa, which renders mussels unsuitable for half-shell trade (Heasman \& de Zwart 2004). Similarly, higher cover by blue mussels $M$. galloprovincialis, arguably the most problematic pest for mussel farming in the region, within the surface $3 \mathrm{~m}$ of long-line droppers may be reduced by lowering mussel long-lines deeper into the water column. However, while moving stock or lowering long-lines into the water column may reduce biofouling, losses in production due to less submerged culture rope or reduced food levels and associated alterations in crop growth would need to be considered. The effects each biofouling species has on mussel growth/economic value would also need to be quantified to informatively assess the feasibility of translocating stock to avoid these species.
Furthermore, in some locations within Pelorus Sound, biofouling cover, specifically blue mussel 'oversettlement', has been observed to occur across the entire length of mussel long-lines (i.e. is not depth dependent), and attempts to avoid this species have to date proven futile (authors' pers. obs). Therefore, an improved understanding of the reproductive seasonality of important pest species may identify 'windows' during which susceptible production stages may be less prone to impacts.

Through mathematical modelling, scientists could utilise site-specific biofouling patterns to inform marine farmers of the geographical distance between farms that might reduce the localised natural spread of problematic biofoulers. This could be achieved by modelling the potential connectivity of biofouling populations between farms and within farming areas, based on their pelagic larval duration and area-specific environmental conditions (Watts 2014). Such information would be particularly beneficial for mussel farmers and local biosecurity efforts, given that biofouling communities are often dominated by non-indigenous species (Tyrrell \& Byers 2007).

\section{Potential steps forward for biofouling management}

This study has identified potential opportunities to improve the management of biofouling risks in Pelorus Sound, such as avoiding locations where known problematic marine pests proliferate. However, avoidance may not always be possible given that marine farmers are often constrained by permitted space allocations. Anecdotal evidence suggests that seasonal patterns could also be exploited. However, for biofouling management through avoidance to be adopted by industry and applied successfully, finer-scale sampling and seasonal patterns would be required to identify 'windows of opportunity' in both space and time. A cost-effective approach would be for industry members to frequently document marine pest presence/absence and abundance during routine farm visits (e.g. during product sourcing). The refinement of the biofouling biomass categories (low, medium and high) used in this study would be one way to achieve this goal, although participants would need to be trained to identify key pests, and there would need to be consistency in how abundance estimates were made. For the latter, it would be worthwhile to involve industry staff (e.g. through a workshop) in developing criteria for the different levels of abundance used, and these levels would ideally relate to likely levels of impact (i.e. high abundance 
of blue mussels = likely high impact). Consideration would also need to be given to the stages of industry production, as biofouling impacts may occur at lower densities for different stages. Data could then be uploaded to an online database, as suggested by Sievers et al. (2014), and used to better inform overall industry practices, as is already undertaken for the detection of harmful phytoplankton (Trainer et al. 2003). Identifying areas containing problematic biofouling species would also be useful to industry members for the development of biofouling management plans that address the spread of biofouling pests via industry vessel and infrastructure/crop movements; i.e. improved vector and pathway management.

\section{CONCLUSIONS}

Realistically, avoidance of all biofouling pests within a growing region is highly unlikely, and farms will continually be exposed to species with a large dispersal potential (e.g. blue mussels) or to those that are widely distributed and reproduce year-round (e.g. Didemnum vexillum). For such species, an improved understanding of actual impacts would underpin management decisions about whether additional risk mitigation measures (e.g. mechanical removal or treatment) are justified. An improved understanding of the environmental drivers of biofouling proliferation would also be advantageous; particularly to understand areas at risk from newly introduced pest species or those pests that are expected to arrive in a region through domestic spread (i.e. those species already present in the country). Also, given that artificial substrates can enhance the recruitment of epibiota, particularly early successional species (Glasby et al. 2007), and to gain insight into local community connectivity, a study of the regional pool of biofouling species available from surrounding native habitats would be required.

Acknowledgements. Sanford Ltd. and Marlborough Underwater Ltd. are acknowledged for their logistical support and field assistance. Thanks also to Rod Asher, Fiona Gower, Lauren Fletcher, Javier Atalah and Aaron Quarterman (Cawthron Institute) for technical support, as well as Niall Broekhuizen and Mark Hadfield (NIWA) for assistance with the Pelorus Sound model graphs, and Mike Page (NIWA) for ascidian identifications. This research was funded by the New Zealand's Ministry of Business, Innovation and Employment (Adding Value to New Zealand's Cultured Shellfish Industry: Maximising Profitability, Minimising Risk). Financial assistance was also provided by the Cawthron Institute Master's Scholarship and the University of Canterbury Master's Scholarship.

\section{LITERATURE CITED}

Adams CM, Shumway SE, Whitlatch RB, Getchis T (2011) Biofouling in marine molluscan shellfish aquaculture: a survey assessing the business and economic implications of mitigation. J World Aquac Soc 42:242-252

Anderson MJ (2001a) A new method for non-parametric multivariate analysis of variance. Austral Ecol 26:32-46

> Anderson MJ (2001b) Permutation tests for univariate or multivariate analysis of variance and regression. Can J Fish Aquat Sci 58:626-639

Anderson MJ (2006) Distance-based tests for homogeneity of multivariate dispersions. Biometrics 62:245-253

Anderson MJ, Ter Braak CJF (2003) Permutation tests for multi-factorial analysis of variance. J Stat Comput Simul 73:85-113

Anderson MJ, Gorley RN, Clarke KR (2007) PERMANOVA+ for PRIMER: guide to software and statistical methods. PRIMER-E, Plymouth

> Antoniadou C, Voultsiadou E, Rayann A, Chintiroglou C (2013) Sessile biota fouling farmed mussels: diversity, spatio-temporal patterns, and implications for the basibiont. J Mar Biol Assoc UK 93:1593-1607

Atalah J, Bennett H, Hopkins GA, Forrest BM (2013) Evaluation of the sea anemone Anthothoe albocincta as an augmentative biocontrol agent for biofouling on artificial structures. Biofouling 29:559-571

Benjamini Y, Yekutieli D (2001) The control of the false discovery rate in multiple testing under dependency. Ann Stat 29:1165-1188

Braithwaite RA, Carrascosa MCC, McEvoy LA (2007) Biofouling of salmon cage netting and the efficacy of a typical copper-based antifoulant. Aquaculture 262:219-226

> Bray JR, Curtis JT (1957) An ordination of the upland forest communities of southern Wisconsin. Ecol Monogr 27: 325-349

Broekhuizen N, Hadfield M, Plew D (2015) A biophysical model for the Marlborough Sounds. Part 2: Pelorus Sound. NIWA report CHC2014-130, Marlborough District Council, Christchurch

Bromley RG, Heinberg C (2006) Attachment strategies of organisms on hard substrates: a palaeontological view. Palaeogeogr Palaeoclimatol Palaeoecol 232:429-453

Cahill PL, Heasman K, Jeffs A, Kuhajek J (2013) Laboratory assessment of the antifouling potential of a solublematrix paint laced with the natural compound polygodial. Biofouling 29:967-975

Callow ME, Callow JA (2002) Marine biofouling: a sticky problem. Biologist 49:10-14

Carl C, Poole AJ, Vucko MJ, Williams M, Whalan S, de Nys R (2012) Enhancing the efficacy of fouling-release coatings against fouling by Mytilus galloprovincialis using nanofillers. Biofouling 28:1077-1091

Carver CE, Chisholm A, Mallet AL (2003) Strategies to mitigate the impact of Ciona intestinalis (L.) biofouling on shellfish production. J Shellfish Res 22:621-631

Cayer D, MacNeil M, Bagnall A (1999) Tunicate fouling in Nova Scotia aquaculture: a new development. J Shellfish Res 18:1-327

> Ceccherelli G, Campo D (2002) Different effects of Caulerpa racemosa on two co-occurring seagrasses in the Mediterranean. Bot Mar 45:71-76

> Chambers LD, Stokes KR, Walsh FC, Wood RJ (2006) Modern approaches to marine antifouling coatings. Surf Coat Tech 201:3642-3652

> Che LM, Le Campion-Alsumard T, Boury-Esnault N, Payri C, Golubic S, Bezac C (1996) Biodegradation of shells 
of the black pearl oyster, Pinctada margaritifera var. cumingii, by microborers and sponges of French Polynesia. Mar Biol 126:509-519

Claereboudt MR, Bureau D, Côté J, Himmelman JH (1994) Fouling development and its effect on the growth of juvenile giant scallops (Placopecten magellanicus) in suspended culture. Aquaculture 121:327-342

Clarke KR (1993) Non-parametric multivariate analyses of changes in community structure. Aust J Ecol 18:117-143

Clarke K, Gorley R (2006) PRIMER v6: user manual/tutorial. PRIMER-E, Plymouth

Cook EJ, Black KD, Sayer MDJ, Cromey CJ and others (2006) The influence of caged mariculture on the early development of sublittoral fouling communities: a panEuropean study. ICES J Mar Sci 63:637-649

> Cronin ER, Cheshire AC, Clarke SM, Melville AJ (1999) An investigation into the composition, biomass and oxygen budget of the fouling community on a tuna aquaculture farm. Biofouling 13:279-299

Curiel D, Bellemo G, Marzocchi M, Scattolin M, Parisi G (1998) Distribution of introduced Japanese macroalgae Undaria pinnatifida, Sargassum muticum (Phaeophyta) and Antithamnion pectinatum (Rhodophyta) in the Lagoon of Venice. Hydrobiologia 385:17-22

Dürr S, Watson DI (2010) Biofouling and antifouling in aquaculture. In: Dürr S, Thomason JC (eds) Biofouling. WileyBlackwell, Oxford, p 267-287

Enright C (1993) Control of fouling in bivalve aquaculture: biofouling has been identified as a major impediment to the development of a commercial oyster culture industry. World Aquac 24:44-46

> Fitridge I, Keough MJ (2013) Ruinous resident: the hydroid Ectopleura crocea negatively affects suspended culture of the mussel Mytilus galloprovincialis. Biofouling 29: $119-131$

Fitridge I, Dempster T, Guenther J, de Nys R (2012) The impact and control of biofouling in marine aquaculture: a review. Biofouling 28:649-669

Fletcher LM, Forrest BM, Atalah J, Bell JJ (2013a) Reproductive seasonality of the invasive ascidian Didemnum vexillum in New Zealand and implications for shellfish aquaculture. Aquacult Environ Interact 3:197-211

- Fletcher LM, Forrest BM, Bell JJ (2013b) Impacts of the invasive ascidian Didemnum vexillum on green-lipped mussel Perna canaliculus aquaculture in New Zealand. Aquacult Environ Interact 4:17-30

Forrest BM, Blakemore KA (2006) Evaluation of treatments to reduce the spread of a marine plant pest with aquaculture transfers. Aquaculture 257:333-345

- Forrest BM, Taylor MD (2002) Assessing invasion impact: survey design considerations and implications for management of an invasive marine plant. Biol Invasions 4: 375-386

Forrest B, Hopkins G, Webb S, Tremblay L (2011) Overview of marine biosecurity risks from finfish aquaculture development in the Waikato Region. Cawthron Report No. 1871, Cawthron Institute, Nelson

Gibbs M, James M, Pickmere S, Woods P, Shakespeare B, Hickman R, Illingworth J (1991) Hydrodynamic and water column properties at six stations associated with mussel farming in Pelorus Sound, 1984-85. NZ J Mar Freshw Res 25:239-254

Gillooly JF, Charnov EL, West GB, Savage VM, Brown JH (2002) Effects of size and temperature on developmental time. Nature 417:70-73

Glasby TM, Connell SD, Holloway MG, Hewitt CL (2007) Nonindigenous biota on artificial structures: Could habi- tat creation facilitate biological invasions? Mar Biol 151: 887-895

Gower JC (1966) Some distance properties of latent root and vector methods used in multivariate analysis. Biometrika 53:325-338

Grant J, Stenton-Dozey J, Monteiro P, Pitcher G, Heasman K (1998) Shellfish culture in the Benguela System: a carbon budget of Saldanha Bay for raft culture of Mytilus galloprovincialis. J Shellfish Res 17:41-49

Gröner F, Lenz M, Wahl M, Jenkins SR (2011) Stress resistance in two colonial ascidians from the Irish Sea: the recent invader Didemnum vexillum is more tolerant to low salinity than the cosmopolitan Diplosoma listerianum. J Exp Mar Biol Ecol 409:48-52

> Guenther J, Carl C, Sunde LM (2009) The effects of colour and copper on the settlement of the hydroid Ectopleura larynx on aquaculture nets in Norway. Aquaculture 292: 252-255

Guenther J, Misimi E, Sunde LM (2010) The development of biofouling, particularly the hydroid Ectopleura larynx on commercial salmon cage nets in Mid-Norway. Aquaculture 300:120-127

Hanson CH, Bell J (1976) Subtidal and intertidal marine fouling on artificial substrate in northern Puget Sound. Fish Bull 74:377-385

Heasman K, de Zwart E (2004) Preliminary investigation on Amphisbetia bispinosa colonisation on mussel farms in the Coromandel. Cawthron Report No. 928, Cawthron Institute, Nelson

Heath R (1974) Physical oceanographic observations in Marlborough Sounds. NZ J Mar Freshw Res 8:691-708

Heath R (1982) Temporal variability of the waters of Pelorus Sound, South Island, New Zealand. NZ J Mar Freshw Res 16:95-110

Hecht T, Heasman K (1999) The culture of Mytilus galloprovincialis in South Africa and the carrying capacity of mussel farming in Saldanha Bay. World Aquac 30:50-55

- Hopkins GA, Forrest BM (2010) Challenges associated with pre-border management of biofouling on oil rigs. Mar Pollut Bull 60:1924-1929

> Howes S, Herbinger CM, Darnell P, Vercaemer B (2007) Spatial and temporal patterns of recruitment of the tunicate Ciona intestinalis on a mussel farm in Nova Scotia, Canada. J Exp Mar Biol Ecol 342:85-92

Karayucel S (1997) Mussel culture in Scotland. World Aquac 28:4-11

Knight BR, Goodwin EO, Jiang WM, Carbines G (2010) Development of settlement model for Marlborough Sounds blue cod (Parapercis colias). Cawthron Report No. 1707, Cawthron Institute, Nelson

Kohler KE, Gill SM (2006) Coral point count with Excel extensions (CPCe): a Visual Basic program for the determination of coral and substrate coverage using random point count methodology. Comput Geosci 32:1259-1269

Lacoste E, Gaertner-Mazouni N (2014) Biofouling impact on production and ecosystem functioning: a review for bivalve aquaculture. Rev Aquac 7:187-196

Lambert G (2005) Ecology and natural history of the protochordates. Can J Zool 83:34-50

LeBlanc N, Davidson J, Tremblay R, McNiven M, Landry T (2007) The effect of anti-fouling treatments for the clubbed tunicate on the blue mussel, Mytilus edulis. Aquaculture 264:205-213

Legendre P, Gallagher ED (2001) Ecologically meaningful transformations for ordination of species data. Oecologia 129:271-280

Lesser MP, Shumway SE, Cucci T, Smith J (1992) Impact of 
fouling organisms on mussel rope culture: interspecific competition for food among suspension-feeding invertebrates. J Exp Mar Biol Ecol 165:91-102

Lleonart M, Handlinger J, Powell M (2003) Spionid mudworm infestation of farmed abalone (Haliotis spp.). Aquaculture 221:85-96

López-Galindo C, Casanueva JF, Nebot E (2010) Efficacy of different antifouling treatments for seawater cooling systems. Biofouling 26:923-930

Lutz-Collins V, Ramsay A, Quijón PA, Davidson J (2009) Invasive tunicates fouling mussel lines: evidence of their impact on native tunicates and other epifaunal invertebrates. Aquat Invasions 4:213-220

> Mazouni N, Gaertner JC, Deslous-Paoli JM (2001) Composition of biofouling communities on suspended oyster cultures: an in situ study of their interactions with the water column. Mar Ecol Prog Ser 214:93-102

Mcintosh CB (1958) Maps of surface winds in New Zealand. NZ Geog 14:75-81

> McKindsey CW, Landry T, O'Beirn FX, Davies IM (2007) Bivalve aquaculture and exotic species: a review of ecological considerations and management issues. J Shellfish Res 26:281-294

McKindsey CW, Lecuona M, Huot M, Weise AM (2009) Biodeposit production and benthic loading by farmed mussels and associated tunicate epifauna in Prince Edward Island. Aquaculture 295:44-51

Metri R, da Rocha RM, Marenzi A (2002) Epibiosis reduction on productivity in a mussel culture of Perna perna (Linné, 1758). Braz Arch Biol Technol 45:325-331

Moate R (1985) Offshore fouling communities and settlement and early growth in Tubularia larynx and Pomatoceros triqueter. $\mathrm{PhD}$ thesis, Plymouth University

> Morlon H, Chuyong G, Condit R, Hubbell S and others (2008) A general framework for the distance-decay of similarity in ecological communities. Ecol Lett 11:904-917

Nanba N, Fujiwara T, Kuwano K, Ishikawa Y, Ogawa H, Kado R (2011) Effect of water flow velocity on growth and morphology of cultured Undaria pinnatifida sporophytes (Laminariales, Phaeophyceae) in Okirai Bay on the Sanriku coast, Northeast Japan. J Appl Phycol 23: 1023-1030

> Narum SR (2006) Beyond Bonferroni: less conservative analyses for conservation genetics. Conserv Genet 7:783-787

Nelson W (2013) New Zealand seaweeds, an illustrated guide. Te Papa Press, Wellington

> Oksanen J (1983) Ordination of boreal heath-like vegetation with principal component analysis, correspondence analysis and multidimensional scaling. Vegetatio 52: 181-189

Oksanen J (2011) Multivariate analysis of ecological communities in $\mathrm{R}$ : vegan tutorial. $\mathrm{R}$ package version $2.0-1, \mathrm{R}$ Foundation for Statistical Computing, Vienna

Oksanen J, Blanchet $F$, Kindt $R$, Legendre $P$ and others (2011) Vegan: community ecology package. R package version 2.0-2, R Foundation for Statistical Computing, Vienna

Oliva ME, Teresa GM (2005) The decay of similarity over geographical distance in parasite communities of marine fishes. J Biogeogr 32:1327-1332

Paetzold SC, Davidson J (2011) Aquaculture fouling: efficacy of potassium monopersulphonate triple salt based disinfectant (Virkon ${ }^{\circledR}$ Aquatic) against Ciona intestinalis. Biofouling 27:655-665

R Core Team (2013) R: a language and environment for statistical computing. R Foundation for Statistical Computing, Vienna
Russell LK, Hepburn CD, Hurd CL, Stuart MD (2008) The expanding range of Undaria pinnatifida in southern New Zealand: distribution, dispersal mechanisms and the invasion of wave-exposed environments. Biol Invasions 10:103-115

> Sievers M, Fitridge I, Dempster T, Keough MJ (2013) Biofouling leads to reduced shell growth and flesh weight in the cultured mussel Mytilus galloprovincialis. Biofouling 29:97-107

Sievers M, Dempster T, Fitridge I, Keough MJ (2014) Monitoring biofouling communities could reduce impacts to mussel aquaculture by allowing synchronisation of husbandry techniques with peaks in settlement. Biofouling 30:203-212

Silina AV (2006) Tumor-like formations on the shells of Japanese scallops Patinopecten yessoensis (Jay). Mar Biol 148:833-840

Simon CA, Ludford A, Wynne S (2006) Spionid polychaetes infesting cultured abalone Haliotis midae in South Africa. Afr J Mar Sci 28:167-171

Soininen J, McDonald R, Hillebrand H (2007) The distance decay of similarity in ecological communities. Ecography 30:3-12

Stæhr PA, Pedersen MF, Thomsen MS, Wernberg T, KrauseJensen D (2000) Invasion of Sargassum muticum in Limfjorden (Denmark) and its possible impact on the indigenous macroalgal community. Mar Ecol Prog Ser 207:79-88

Thomsen MS, Wernberg T, Stæhr PA, Pedersen MF (2006) Spatio-temporal distribution patterns of the invasive macroalga Sargassum muticum within a Danish Sargassum-bed. Helgol Mar Res 60:50-58

Trainer VL, Eberhart BTL, Wekell JC, Adams NG, Hanson L, Cox F, Dowell J (2003) Paralytic shellfish toxins in Puget Sound, Washington state. J Shellfish Res 22:213-223

Tsujino M, Hori M, Okuda T, Nakaoka M, Yamamoto T, Noda T (2010) Distance decay of community dynamics in rocky intertidal sessile assemblages evaluated by transition matrix models. Popul Ecol 52:171-180

Tyrrell MC, Byers JE (2007) Do artificial substrates favor nonindigenous fouling species over native species? J Exp Mar Biol Ecol 342:54-60

> Underwood AJ, Anderson MJ (1994) Seasonal temporal aspects of recruitment and succession in an intertidal estuarine fouling assemblages. J Mar Biol Assoc UK 74: 563-584

Underwood AJ, Petraitis PS (1993) Structure of intertidal assemblages in different locations: How can local processes be compared? In: Ricklefs RE, Schluter D (eds) Species diversity in ecological communities: historical and geographical perspectives. University of Chicago Press, Chicago, IL, p 39-51

Uribe E, Etchepare I (2002) Effects of biofouling by Ciona intestinalis on suspended culture of Argopecten purpuratus in Bahia Inglesa, Chile. Bull Aquacult Assoc Can 102:93-95

> Valentine PC, Carman MR, Blackwood DS, Heffron EJ (2007) Ecological observations on the colonial ascidian Didemnum sp. in a New England tide pool habitat. J Exp Mar Biol Ecol 342:109-121

Watts AM (2014) Biofouling patterns and local dispersal in an aquaculture system in the Marlborough Sounds, New Zealand. MSc thesis, University of Canterbury, Christchurch

Woods C, Floerl O, Hayden BJ (2012) Biofouling on Greenshell ${ }^{\mathrm{TM}}$ mussel (Perna canaliculus) farms: a preliminary assessment and potential implications for sustainable aquaculture practices. Aquacult Int 20:537-557 